\title{
First Year Students' View of Architecture
}

\author{
Hakan Anay1๑, Ülkü Özten² ๑ \\ ${ }_{1}^{1}$ Professor, Engineering and Architecture Faculty, Eskisehir Osmangazi University, Turkey. Email: info@hakananay.com \\ ${ }^{2}$ Associate Professor, Engineering and Architecture Faculty, Eskisehir Osmangazi University, Turkey. (Principal contact for \\ editorial correspondence),Email: info@ulkuozten.com
}

\begin{abstract}
Purpose

The present study investigates architecture students' pre-established schemata or prejudice structures towards architecture before their formal education starts. This would be particularly deemed important since architectural pedagogy might be tweaked or even reformulated accordingly.

Design/Methodology/Approach

The research employs "content analysis" which is a method that uses set of tools and procedures to read texts for generating knowledge-based inferences. On such a ground, the research is based on single-sentence answers given to a simple question asked to students: "what architecture is all about." and the recordings of a follow-up open-ended discussion with the students on the initial findings. The data is evaluated both quantitatively and qualitatively.

Findings

Findings indicate a series of pretexts in students' responses, particularly a residing (historical) determinism, a belief in zeitgeist, a conservatism, a pessimistic, passive understanding of architecture. On the other hand, they did not relate architecture to newness, change, difference, innovation, and they did not conceive architecture as an agent of these aspects. Research shows that students' horizon of expectations and their preconceptions about architecture seem to be quite a mismatch with any trajectory of architectural education tradition that might take these notions as essential to itself and its intellectual core.
\end{abstract}

\section{Research Limitations/Implications}

The study is aimed to be part of baseline data for carrying out future investigations, a step toward more systematic analysis of changing state of today's architectural education and a larger/global effort to map this phenomenon with its possible effects in architectural education.

Originality/Value

The study makes an original contribution to knowledge by being one of the first studies to focus on the question of "what architecture is all about" on behalf of the first-year architecture students in Turkey.

Keywords: Architectural education, architectural pedagogy, architecture, schemata, prejudice structures 


\section{INTRODUCTION}

...architects who have aimed at acquiring manual skill without scholarship have never been able to reach a position of authority to correspond to their pains, while those who relied only upon theories and scholarship were obviously hunting the shadow, not the substance. But those who have a thorough knowledge of both, like men armed at all points, have sooner attained their object and carried authority with them.

\section{- Marcus Vitruvius Pollio}

Trying to give an answer to the ultimate question "what is architecture," and trying to conceptualize "what architecture was all about," is a longstanding endeavor, attempted by many throughout the history. We do not know for sure if the architects of Göbeklitepe, one of the oldest architectural piece known to us, circa $10^{\text {th }}$ millennium BC, were aware of what they were doing and why, but, we might suspect that they did so. Thinking as such would not be far reaching, since for example the first text about architecture that is accessible to us today, namely Vitruvius' $D e$ Architectura, to the degree considered as some type of a "guidebook," to that degree it is a means of theorizing "architecture," and an accompanying attempt to answer the ultimate question, "what architecture is all about" (Vitruvius 1914) ${ }^{1}$. The earliest attempt also illustrated that not only architecture might mean many things all at once, but also no matter how carefully formulated our conception about it, and no matter how inclusive and comprehensive it was, it would sooner or later, and easily be refuted by others, at least by emphasizing other facets of architecture. For example in his "Architecture, Essay on Art," EtienneLouis Boullée's answer to Vitruvius' conception of architecture as "art of building," architecture conceived as an intellectual product, a product of the mind, a creative endeavor, is a well-known illustration of such attempts (Boullée 1976) ${ }^{2}$. A more recent one is Bernard Tschumi's answer to Nikolaus Pevsner's famous quote in his book An Outline of European Architecture, stating that "A bicycle shed is a building; Lincoln Cathedral is a piece of architecture" (Pevsner 1957). Tschumi contends in his Architecture Concepts: Red is Not a Color that actually it is just the reverse, "A bicycle shed with a concept is architecture; a cathedral without one is just a building" (Tschumi 2012).

If the title is taken as it was, almost a tautology, setting aside Hans Hollein's (1968) essay "Everything is Architecture," history of architecture is full of statements of architects, philosophers, scholars, even politicians, trying to describe what architecture was, most of which are either going against what precede them or mostly incompatible with each other3.

One might think perhaps written language came short to describe architecture, or some would say a formula is not only impossible but also needless. Apparently, all is because of the nature of architecture, that is based on architectural problems mostly ill-defined in nature ${ }^{4}$, the process itself is on the one hand indeterminate, on the other, epistemologically
1 An original manuscript of De Architectura was written in Roman between 30 and 15 $\mathrm{BC}$ to be presented the ruler of the Roman world, Augustus Caesar.

2 Boullée's (1728-1799) Essai sur l'art, Architecture was originally written in French. It is a compilation of part of Boullée papers and notes.

3 For a detailed understanding of the architectural quotes see, Laura Duschkes (2012), The Architect Says: Quotes, Quips, and Words of Wisdom, Princeton Architectural Press.; and also see related more popular web sites available at:

https://www.goodreads.com Lquotes/tag/architecture, https://www.arch2o.com/fa mous-architecture-quotestime/,

https://www.azquotes.com/ quotes/topics/architecture.h tml,

http://www.notable-

quotes.com/a/architecture q uotes.html,

(accessed 18 October 2018).

4 About ill-defined problems see (Reitman 1964); (Newell 1969); (Simon 1973); (People 1982); (Voss \& Post 1988); (Johnson 1988). 
fed from vast sources, and while the knowledge is mostly tacit, the equation (if there is such thing) from which architectural solutions come out is disastrously complicated. Architecture is art, architecture is science, architecture is about technique, about engineering; architecture is about context, society, human beings, it pleases, gives message, talks, you can use it, see it, live in/with it, it is intellectual, cultural, physical, political, financial, it express values, symbolize things, it houses, it shelters, it protects, and often it is about many of these at once (Figure 1). So any attempt to define such a phenomena, distill it down to its essence is not only futile, but if done so, the outcome might be easily refuted. However, any description attempt might bear the element of truth; actually, some might give a rigorous, plausible answer to the question "what architecture was," and develop an understanding of architecture. However, more important, these are the means of one's view of architecture solidified into a verbal, written form.

Figure 1. Multifarious facets of architecture (by the authors)

${ }^{5}$ About schemata theory and some of its applications to the field of architecture and design see (Piaget 1952); (Piaget \& Inhelder 1969); (Rumerhart 1980); (Bartlett 1995); (DiMaggio 1997); (Webster 2008); (Devlin 1990);(Jacob 1993);(Minsky 1997); (Craig 2001); (Akin 2001) ;(Akin and Akin, 1996) ;(Lawson 2004); (Kohls and Scheiter 2008); (Oxman 1994); (Oxman 2005).
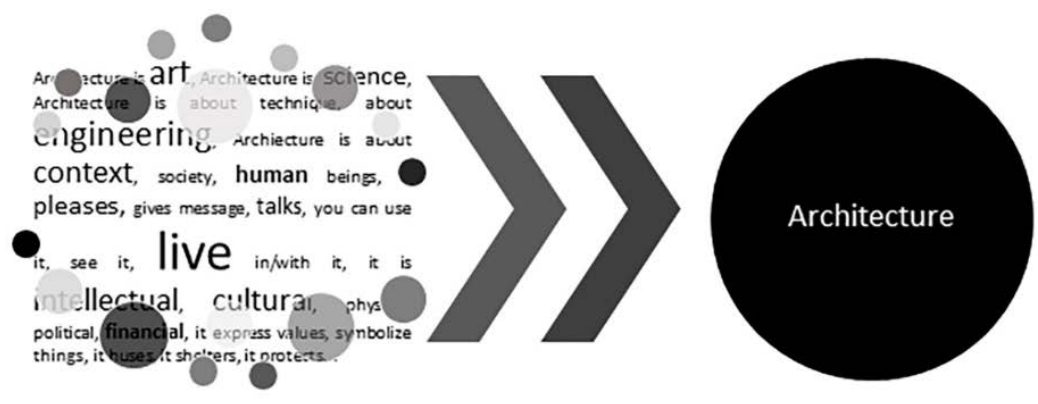

\section{What is}

The epistemological roots of this position refer to multiple sources from contemporary philosophy. From a wider perspective, to use a term from philosophical hermeneutics of Hans Georg Gadamer, these are the means of giving a portrait of one's "prejudices" and "prejudice structures" about architecture (Gadamer 1976 ), or to use a term from reception theory of Hans Robert Jauss , these are the means of representing one's "horizon of expectations" concerning architecture (Jauss 1970). Prejudices or expectations are not only required for one to see the world, but also understand, interpret, and evaluate what surrounds us, whether intellectual or physical, including architecture as a profession, as a concept, as a product or whatever we attribute architecture to be. Accompanying learning and cognitive theories such as Schemata Theory 5 and Jan Piaget's cognitive theories (Piaget 1952; Piaget \& Inhelder 1969) in parallel suggest that such structures are the pre-requisites and precursors of all types of learning, and learning itself is nothing but establishing such a schemata or transforming the existing ones into something desired. As such, learning could be interpreted as establishing prejudice structures or schemata in one's minds tailored to fit the needs and specificities of a certain profession's requirement (Figure 2). Moreover, at any point, (before, during, and at the end of a formal 
education,) one's view of the world would project one's schemata, one's prejudices, or one's expectations. Therefore, any attempt trying to theorize and conceptualize architecture means externalization of one's view of architecture. So, attempting to formulate "what architecture was all about," actually not amounts to saying "architecture is..." but rather saying, "this is how I view and conceive architecture." Since such externalization reflect their formulator's worldview, as well as his or her schemata, in an externalized, recorded, and thus solidified state, to use Karl Popper's terms, these might be subject to objective investigation (Popper 1945; Popper 1974).

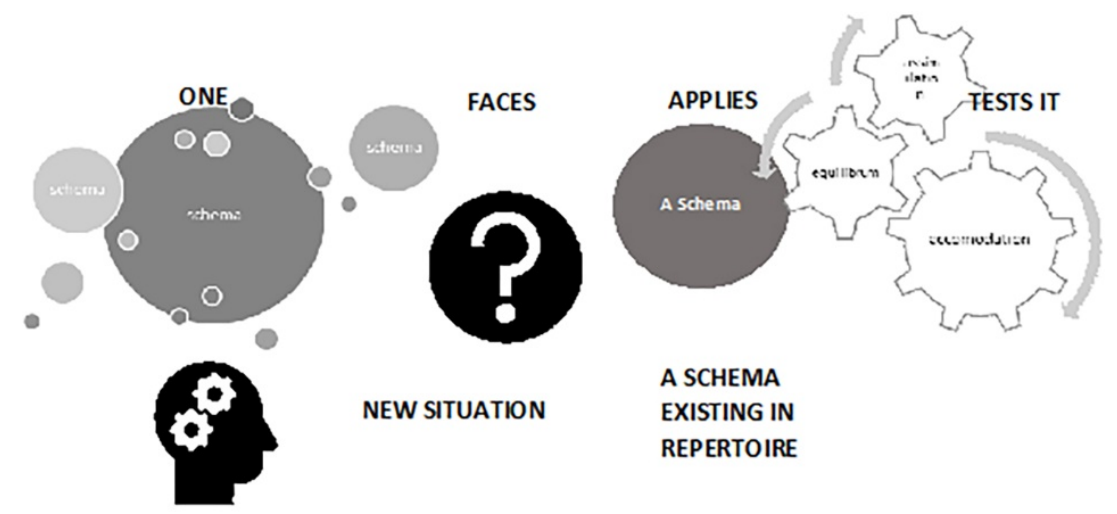

Departing from the abovementioned framework, the present study investigates architecture students' pre-established schemata or prejudice structures towards architecture before their formal education starts. Apparently, it would vary considerably between individuals, but we could easily claim that each generation would carry the marks of their own era in their mindsets and investigating these patterns will indicate a holistic view of the phenomena, the "material" that we are confronted with as educators. This would be particularly important since architectural pedagogy might be tweaked or even reformulated accordingly.

\section{METHODOLOGY}

The present research is based on first-year architecture students' answers to the question, "what architecture is about." In total, 105 students were involved in the study. Each student was given an unlimited time to answer the question in isolation from any media. Given the question, the students were asked to formulate and write down their response it in only one sentence. This was for forcing them to distill their understanding of architecture to its precise essence, and formulate their answers accordingly. Namely, to ensure that they formulate a concise view of their notion and understanding of architecture to include what was essential while excluding the non-essential aspects, for them. Methodologically, if were there more than one sentences, only the first one was considered.
Figure 2. Piaget's theory of schemata. (by the authors) 
6 Researchers were professors of architecture having about 23 years of teaching experience in the academy, and having 23 years of research experience, particularly focusing on architectural education.

7 Content analysis is a method, a systematic reading, focused on meanings, concepts, intentions, and references. It is a method that uses set of tools and procedures to read texts for generating knowledge-based inferences. About "content analysis" see (Weber 1990) (Krippendorff 2004).
In the first stage, gathered data was evaluated both quantitatively and qualitatively by two researchers, independently. ${ }^{6}$ Here, reliability and validity of data mainly comes from first-hand expressions of the students externalized and solidified in written form. Secondly, it comes from its degree of reproducibility, by being independent of its researchers/interpreters. And thirdly it comes from selection of researchers/interpreters by making sure of they are equally capable individuals and while observing, generating and interpreting data, independent from each other. Researchers first read the statements to identify the notions, then count and categorize them to achieve a quantitative portrait of the phenomenon. Then, all notions are examined in their context, qualitatively, to see and understand how and in what sense they were employed, and in some cases, how they were employed with relation to other notions; a content analysis was employed. ${ }^{7}$ As a final stage two analyses were brought together to compare and interpret the findings and turn the findings into a preliminary report.

As a follow-up stage, in an open discussion, the initial findings, as they were turned into a systematically sorted and structured report, were shared with the students and their responses were recorded as a follow up verbal interactive stage. The data gathered from the recordings were utilized to evaluate and interpret the initial report, and reconsider it to arrive at conclusions. In this session, researchers focused on making a conversation with students to obtain a conceptual clarity in regard to remarkable identifiable explanations observed in texts in the previous stage. The process proceeded with a micro-level analysis for contextualizing their in-text concepts and categories that students tended to underline in their texts. Such a stage explains how conscious/determinant were students to choose and use such words and categories in answering questions. Also, it clarifies in which context or to what extend they use them.

Methodologically, the findings of the first stage are reported here without any modifications, followed by the findings coming from the second stage, as they were interpreted according to the findings from the first. In each section a bottom-up discussion about the findings were given. Conclusion, established upon the both, rather tries to draw a top-down, holistic picture of the findings.

\section{FINDINGS AND DISCUSSION}

\section{First Stage}

As one might expect, first finding that came out of the observations is that architecture is never seen as a pure, single entity in itself, but a complex phenomenon that has many, sometimes conflicting and incompatible facets. It is seen that students first tried to contextualize architecture by using 275 concepts in total with a mean value of 2.61 concepts per expression used towards explaining what architecture was about, showing that they conceived architecture as a multi-dimensional phenomenon. In congruence, more than half of the students (60) saw 
architecture itself as either a "combination," or a "mediator" between many things. Since students used multiple expressions to enhance their expressiveness, resulting data were need to be analyzed and interpreted. As the data was examined and interpreted, it was observed that students' responses to the question "what architecture is all about," might be categorized under the following headings according to the nature of the expressions (Figure 3). These categories were not given to students, but came out of their answers.

What architecture is about?

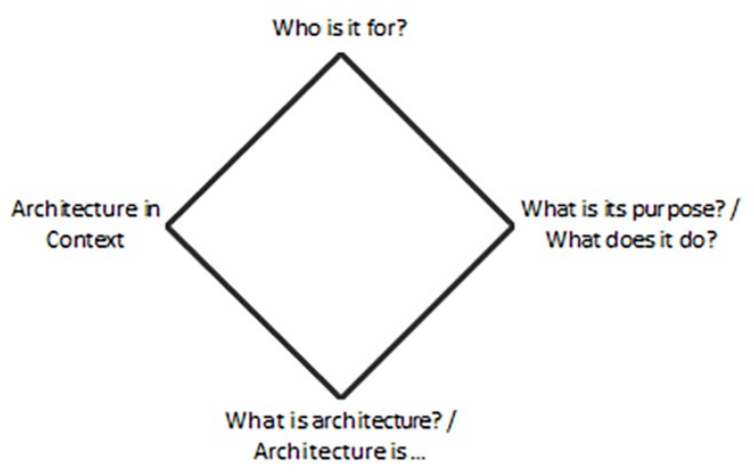

\section{Who is it for?}

A number of issues that came out of students' descriptions was to answer the question "what architecture is about," by referring to the question "who is it for?" (Figure 4)

Who is it for?

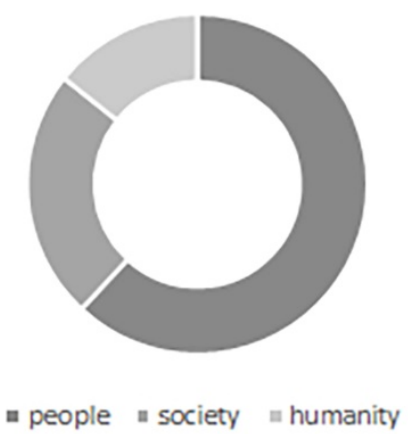

Students seem to be giving one big answer to this question by stating that architecture is about "people," "society," and from a larger perspective for "humanity" (42). Actually, these seemingly similar issues are quite different in terms of context and content. The term "people" is more frequently used (26), and it is more individualistic, emphasizing the diversity and independence, as compared to "society," a less referenced notion (10), that is essentially refers to a "community," an aggregation, organization of people. Both lack the emphasis on the element of time,
Figure 3. Four main headings as distilled from students' expressions (by the authors)

Figure 4. Obtained main patterns for the category of "who is it for?" (by the authors) 
while the second might be more related to values, cultural aspects, etc. "Humanity," on the other hand (6), seeming to be pointing to an abstract, collective, holistic, inclusive and unprejudiced understanding of human race in its cultural, physical, or historical context, including past, present and future all in one.

As far as the individuals (is people) are concerned, there seems to be "implied" or directly stated notion of betterment and improvement, but the influence and affect is both from architecture to people, and people to architecture, as architecture is not only affected by the needs and lifestyle of individuals, but also affective upon them. On the other hand, as far as the society is involved, the notion of change and cultural influences are more emphasized, but this time influence seems to be mostly from society to architecture, as a determinant. Humanity on the other hand, is generally related with bigger ideals, mostly philanthropic.

Although students tend to recognize architecture as "art," it has never been interpreted as phenomena in, or for, itself. In parallel, its autonomy has never been emphasized (i.e. as in "art for art's sake")

\section{What is its purpose, what does it do?}

Some students preferred to answer the question "what architecture is about," by referring to its purpose, or to what it does (Figure 5).

Figure 5. Obtained main patterns for the category of "What is its purpose? / What does it do?" (by the authors)
What is its purpose? / What does it do?

a function, utility $\mid$ giving us feelings $\mid=$ making change $\mid$ communicating with us

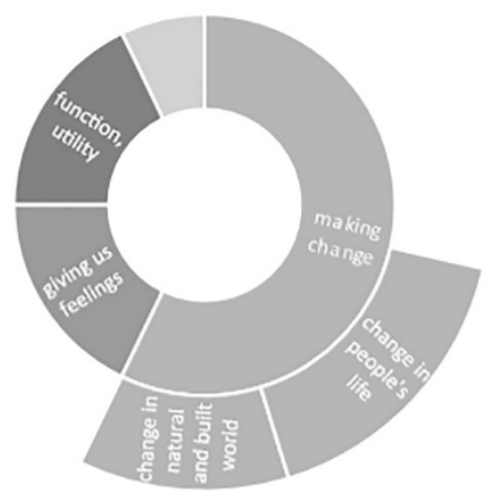

As one might expect, architecture's utility, its function, or use is widely emphasized in the descriptions (15). Students believed that architecture must answer to people's needs. Although it might be considered under this issue, some of the students took a more phenomenological stance claiming that architecture is primarily about feelings, and giving us feelings (15), particularly putting emphasis on notions such as pleasure and happiness. As such, although it might be easily interpreted as "purpose," this is quite different from mere utility, actually seeming to be competing with soulless or mechanical notions such as "use" or 
"function." However, in both cases definition is related with serving people, their needs, lifestyle, and for their happiness and pleasure as well. This category of descriptions could be investigated under the umbrella term "change." Architecture in these expressions are associated with some type of change (24) whether this change involves change in people's life (14) or change in natural and built environment (10). Change in these conceptions are either imply, or directly associated with, philanthropic motives. However, change, and associated notions such as innovation, newness, etc. are never attributed to architecture itself, illustrating that architecture in this conception is rather conceived as some type of device. Few students emphasized the communicative or symbolic function of architecture (6). To these, architecture should either be communicating something or "mean" something, o a symbol of something. This issue is particularly shared here that seemingly one "big" aspect of architecture has not been seen as an important aspect of architecture by the students to describe it.

\section{What is architecture, or architecture is ...}

This category of replies might be interpreted as mostly an attempt to answer the question "what is architecture," or used to complete the expression "architecture is ..." rather than "architecture is about ...." (Figure 6). However, at the same time, they give insights about students' understanding of "what architecture is about."

One of the most striking and dominant expressions under this category is the ones that interpreted architecture as art (22). This was in a sense expected, since it is an age-old notion that architecture is an art, in fact mother of all arts. This category is often positively associated with beauty and aesthetics, and feelings and pleasure as well, while in some cases art is contrasted with science and construction.

As it was previously stated above, both in its associations with the notion of change (24) and worldmaking (8) as well, architecture is conceived as a "device." In addition, some of the students saw architecture also as a means of some type of communication (6), in all cases it was taken as a means rather than ends.

In a number of expressions (12) architecture is interpreted as a projection of some type of idea or concept imposed on the world, on people's lives, and on nature. There are also unique answers, or answers with low frequency, those are worth to mention here.

Relating architecture with its parent discipline "design" might also be expected, but a few students deemed architecture as about "design" (8). Similarly, architecture as "problem solving" is also one of such aspects; quite e few of students emphasized architecture as "problem solving" (2). Only one student interpreted architecture is "a religion," a set of rituals and beliefs to be followed. 
What is Architecture?/Architecture is...

art $=$ device $=$ projection of an idea $=$ design $=$ problem solving

Figure 6. Obtained main patterns for the category of "What is architecture? / Architecture is..." (by the authors)

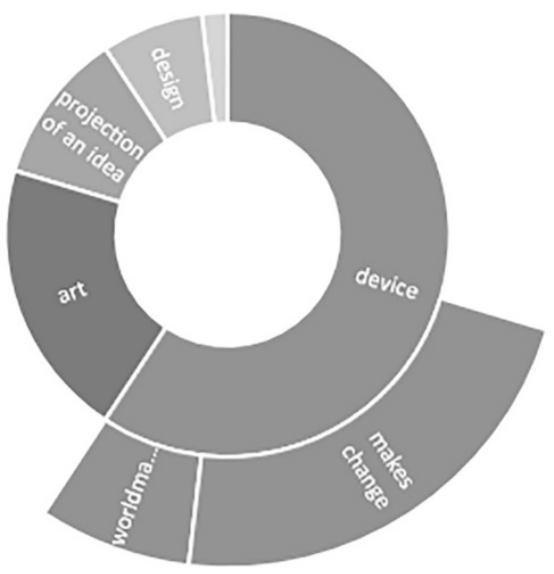

\section{Architecture in context}

It is seen that, many expressions tried to contextualize architecture or try to take it in some context while attempting to explain what architecture was about (57). Within this category, three major contextual layers were identified: physical, historical and cultural (Figure 7).

One of the dominant patterns was architecture's relation with its physical surrounding whether it is natural or manmade (42). Students seem to be taking architecture as a part of a larger whole, for example a natural setting or an already established built environment. Observations showed that the main emphasis is on architecture as a part of a larger whole, or, architecture's responsibility for what surrounds it (36), especially "nature" (32), or sometimes architecture's power to make new environments (namely "worldmaking") (8) and its power to change (20) them was emphasized.

Another contextualization effort involves history (16). By nature, such a contextualization involved quite a different set of relations. Students seem to be very well aware of the fact that architecture is related with (its) history, where the emphasis is on the "continuity and respect" (10). As far as the time and history is concerned, architecture is equally seen as a thing of the "present" (3), and in addition, deemed as a making that would influence the "future" (3). Actually, when viewed as a whole these observations point to a very complex understanding of architecture, conceived in terms of time and history. 


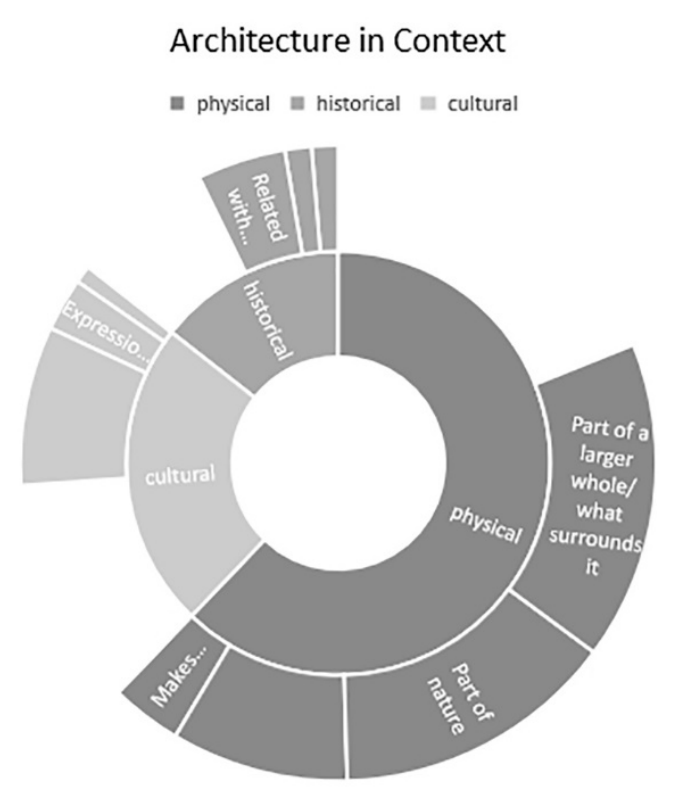

This final evaluation combined with the so-called architecture's power and will to change, and its capacity of "worldmaking," mentioned previously, indicates quite a powerful understanding of architecture as about context making or context changing, and architecture itself as a device of change (however this do not apply to the following issue).

Students seem to be very well aware of the fact that, a cultural product itself, architecture's relation with culture. In answering the ultimate question, they employed culture and cultural issues (26) as a means of contextualization of the notion of architecture. Architecture is seen as (or must be) a "projection of a certain cultural environment" (18), or should be "expressing a certain lifestyle" (6), or "worldview" (2). However, culture's relation as a context upon architecture in students' understanding of architecture rather seemed to be one-way as compared to the previous two categories. This is contrasting with the previous cases, since in them, architecture was seen as a part of certain context, and it was seen as a maker, contributor, and modifier of that precise context. Here, although architecture is very strongly related with cultural context, none of the students mentioned about architecture's contribution and affect back upon that context. With this respect, notions of worldmaking and change do not seem to be applicable to architecture's relation with culture. While first points to physical world, the second as having a one-way formative affect upon architecture but not vice versa.

\section{What is not included?}

Expressing what architecture is all about, students seem to be not aware of, or perhaps tend to ignore or suppressed some aspects of architecture. Suppressing some while foregrounding others was the part of the game but still, what is not included is also worth to mention here to present the other side of the coin and make the drawn portrait's contours crisper (Figure 8).
Figure 7. Obtained main patterns for the category of "Architecture in Context" (by the authors) 
Figure 8. Barely cited and not cited aspects of architecture (by the authors)

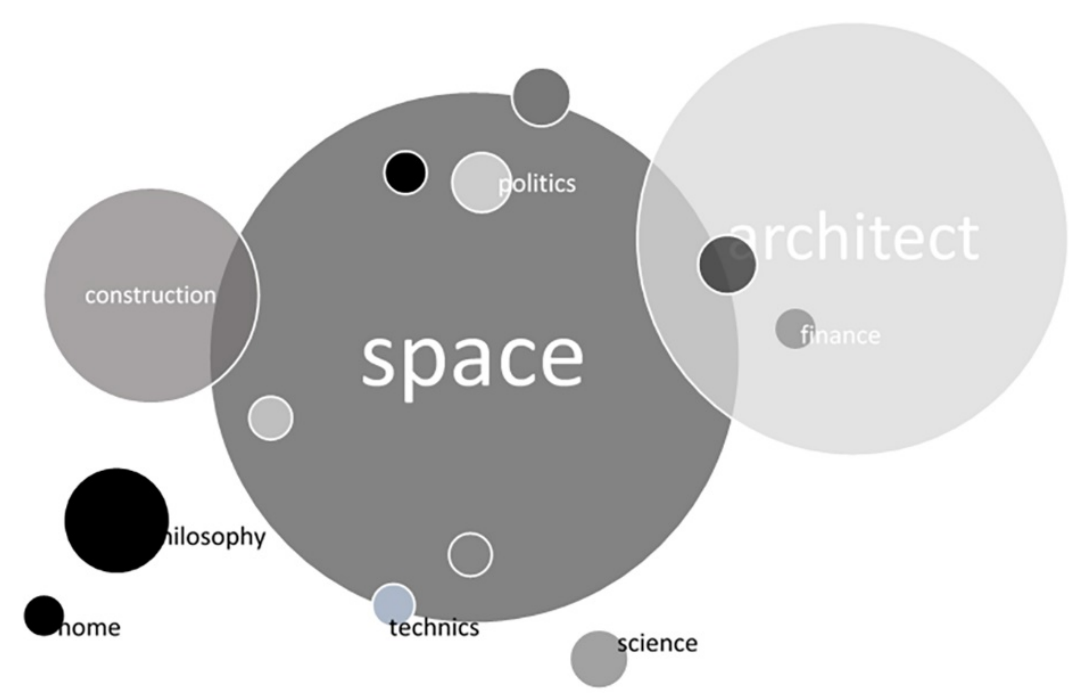

First, perhaps most striking is that students almost never referred to architecture's materiality, its constructive or material aspects. Beside this, technical issues those might be associated with architecture are also scarcely referred (4). The notion of science (4), although sometimes used is often referred to as something contrasting with or in addition to some essence such as aesthetics, feelings, etc. Architecture has never been interpreted as shelter, its homing responsibilities were seemed to be totally ignored, and "space" is absent in all expressions. A few expressions mentioned issues such as politics (1), finance (1), and power (1). Architecture's relation with philosophy and its own philosophy is scarcely (3) referred.

Finally, the word "architect" was never used in any of the expressions.

\section{Second Stage}

In congruence with the findings of the first stage, students strongly agreed with or tend to accentuate that architecture is not and cannot be a pure, single entity in itself, but involves many things. The emphasis was still on the notions of "combination," "mixture of."

\section{Discussions on who is it for?}

As the tripartite structure (humanity, society, and people) that came out of the initial study is shared with them, students seemed to be found it informative, and from the discussions, they seemed to be very well aware of the fact that these were actually quite different from each other in terms of content and their contexts. Out of the discussions, two notions came out to be significant, students believed that architecture is for people, but since it should be projecting the values and beliefs of the society, it also belongs to the domain of societies. Here discussions were branched into two distinct lines of argument: first, they seemed to be disturbed with the understanding of architecture merely belonging to human beings (for example what about animals?), and they tended to 
emphasize the differences between the societies, and discuss how architecture should respond to these differences.

Their emphasis on philanthropic issues, on betterment and improvement, and related with this the notion of change are strongly transformed towards a certain direction in the follow-up discussions. Students seemed to be holding firmly to these ideas but they strongly rejected that architecture has right to change and say something about people's life and society. They seem to believe that architecture's, relation with the society and its social and cultural values could only be one-way from society to architecture, and they believed that society's values and beliefs are the direct shaping forces, or determinants upon architecture.

\section{Discussions on what is its purpose, what does it do?}

Students seemed to be holding firmly to their understanding architecture as something of utility, something that is about function, or use. Students strongly emphasized that architecture must answer to people's needs. As far as the notion of utility was concerned, their accompanying conceptualization "architecture is primarily about feelings, and giving us feelings," were considered as a different category, conceptualized as something different from "utility." As compared, while utility of the first kind is seen as more essential while the second category is seen as something of a flavor, or a required addition to the first.

Understanding of architecture involving change is also strongly modified here towards a certain direction. Students agreed that their initial responses stating that architecture is about change, but they strongly rejected the notions that architecture has power and right to change things, or architecture has something to do with such an understanding of change. Students emphasized that as the people's life change, environments change, cultures and societies change, architecture must on the one hand keep up with these changes on the other submit itself to the conditions coming out of these changes. They believed that only in this sense, architecture might be about change. This position seems to be in congruence with the initial findings, that architecture was never associated with innovation, newness, and such.

\section{Discussions on what is architecture, or architecture is ...}

This category involves a considerable modification upon the initial findings. As the students were informed from the findings coming out of the first answers, that, architecture was seen as an art, they strongly objected. They primarily brought forward the notions that architecture is utility, it is about use, it is about people, society, and similar previously accentuated dominant themes, as an opposition to the statement "architecture is art". On the other hand, no one denied that architecture involves artistic aspects. They seemed to be tending towards, architecture considered as art, is something far from its primary essence, but pointing to architecture's secondary (perhaps less important) aspects such as looks, beauty, aesthetics, which actually are some type of 
"additions" made to the essence. Paradoxically, they also seemed to require this "addition" as mandatory, without which architecture is not architecture at all.

\section{Discussions on architecture in context}

Their attempts towards contextualization of architecture was presented to the students, as it was given above. They were surprised to see their responses involved such a contextualization.

Here students firmly hold onto their initial responses with a number of modifications. In architecture's relation with its physical surrounding, nature came forward more while students tend to be suppressing manmade environments such as cities as secondary. So architecture was considered as something that should be respectful to, and obedient to its surrounding, and what lies before it meant more the "natural" setting than the "man-made" setting.

Contextualization efforts involving history is also further supported, but with modifications. While students seemed to be agreeing that architecture is a part of the history, they got history as something of the past, but not of the present and the future. Therefore, they strongly rejected that architecture could shape future, or power and responsibility to do so. However, they emphasized that throughout the course of time, architecture conformed to the specificities of that period, and it should be conforming to the ones, coming with the future.

Therefore, the initial findings implying that students might be seeing architecture as about context making or context changing, and architecture itself as a device of change is refuted here.

Architecture being a cultural product itself and architecture's relation with culture is strongly accentuated. Students further emphasized that architecture should be conforming to the cultural environment, must be expressing the specificities of the society it belongs. In congruence with the initial findings, culture's relation as a context upon architecture in students' understanding of architecture rather seemed to be one-way. They believed that architecture could only be a part of a certain cultural context, but has no power and right to shape, contribute to that precise cultural context.

\section{Discussions on what is not included?}

Students were also asked why they did not include some aspects or why they did not associate architecture with a number of notions.

As students were told that they forgot to mention about architecture's material being, its construction, its stability they argued that there is no need to state these aspects since it is obvious, and since these are "already" there. This is similar to the notions such as shelter, and homing, as either students did not find these worth to mention or they were taken as granted. Absence of the notion of "space" is received with silence and kept unanswered. 
The purpose of this article was to uncover first year students' view of architecture (their pre-established schemata or prejudice structures towards architecture) through content analysis. To this end schemata theory is used as an underlying theoretical perspective. Mainly a descriptive qualitative exercise was employed to answer the research question: "What architecture is all about". Data collection and following analyses allow the researchers to focus on a mismatch between trajectory of architectural education tradition and the first-year students.

As it was mentioned earlier, students seem to be very well aware of the fact that architecture might be about many things, sometimes in conflict with each other, in combination. As the overall picture checked, it could be easily concluded that students locate architecture closer to humanities, social sciences and art, rather than to natural sciences. Students' tendency to locate architecture within some type of cultural, intellectual and/or physical context while trying to describe it was interpreted as neither works of architecture nor architecture with a capital " $A$ " were seen as isolated entities, or phenomena, conceived and able to exist within a contextual vacuum. Students seemed to be very well aware of the fact that architecture is tied to what existed before and outside it. On the other hand, architecture's relation with social, cultural and historical contexts were seen as one-way, from the context, as a directly forming or determining agent upon architecture. Although its artistic side is acknowledged, the idea of architecture as art is strongly rejected primarily under the pretext of architecture's utility, and function. When viewed from a wider perspective, following interpretations might be made. Architecture's utopian (in the term's both senses) or idealistic dimensions, as these were conceived by modern architecture at the beginnings of the last century, seem to be suppressed in architecture's present understanding by the first-year students ${ }^{8}$. Categorically, architecture's relation with humanity, society or the individuals were placed at the core of the definitions, but architecture's power and will to change people's life, its responsibilities to make a better society and living environment conceptualized in a different way. In its relation to humanity, society or the individuals, architecture is rather placed in a passive position, not an actively forming, or even contributing agent, but rather a subordinate that should follow what was brought before it, follow the steps of the society. Therefore, philanthropic aspects of architecture were seemingly there, and emphasized by statements such as "for people," "for better life," "for improvement," "for better society," "for better environment," but it seemed that "for" in these expressions imply a resignation from architecture's operational power, and a submission to whatever comes before it ${ }^{9}$. This is quite interesting, and on the one hand implying a type of determinism, particularly a certain genre of it, called "historical determinism," on the other, pointing to an implied belief in so-called zeitgeist ${ }^{10}$. For example, students always claimed that architecture's relation with the cultural and historical aspects of life is/must be one way, from these phenomena, as absolute determinants, to
8 About utopia and the utopian content of architecture see (Tafuri1976); (Rowe \& Koetter 1984) ;(More 1988), (Vidler 2001) ;( Choay 2005); (Baudrillard 2007); (Jameson 2012).

9 About utilitarian architecture and philanthropy by architecture see (Harries, 1997);(Cary, 2017). There is a detailed discussion of it in the Collage City (Rowe \& Koetter 1984). In addition to them, there are many web sources grounded onto the issue. Some of them are available at: https://www.smh.com.au/o pinion/we-can-build-betterfutures-through-

philanthropy-2015011812 smrl.html

https://unhabitat.org/philan thropic-architect-commitsto-build-20000-refugee-

homes-in-north-kenya/ https://archinect.com/featu res/article/150008944/arch itects-of-social-

responsibility-views-ofhumanitarian-architecturein-practice (accessed 18 October 2018).

10 About zeitgeist, teleology and historical determinism see (Hegel 1943); (Popper 1963); (Gombrich 1969) ;(Popper 1974);(Colquhoun 1981); (Rowe \& Koetter 1984);(Anderson 1987). 
architecture. In parallel, history was seen as essentially something about the past, and its relation with architecture is emphasized according to this understanding. As far as the future is concerned, it is something that one must yield itself, so must architecture, that it should always follow the change, namely jump on the latest bandwagon, and accept what was given without criticizing it. This position is further supported in student's conception of architecture as concerning art, but to the degree, it is about some type of aesthetics, or beauty, an "addition" to architecture, but not viewing architecture something concerning inquiry, difference from what exist before it, innovation, or a change for and in itself, or a device.

Students' conception of architecture was rather pessimistic since they seem to believe that as architects, we cannot change anything, we do not have right and power to say something, and change is something that we follow. They were also conservative about almost everything, since they believe architecture should conform to history, culture, and society, namely the status quo.

As a whole students' horizon of expectations and their preconceptions about architecture seem to be quite a mismatch with any trajectory of architectural education tradition that might take notions such as newness, change, difference, innovation as essential to itself and its intellectual core, and architecture as a device to fulfill its philanthropic

11 We mean the intellectual content of Modern Architecture, artistic and architectural avant-garde of the 20th century, the Bauhaus, the makings of the so-called Texas Rangers of Cornell, and genuine descendants of these and similar avant-garde "schools." tasks ${ }^{11}$. Surely docking ourselves at the safe-harbor of technological determinism and its accompanying digital determinism, as many of the present pedagogies do, would be an option, but If we are to keep these "values" central to architecture, the portrait drawn here seems to be quite a challenge to us educators that we would be possibly addressing in the near future. To this end, the findings might be resulted in various conclusions.

One of the conclusions obtained from these findings might be to think that there would be a need to converge what pre-educated minds have in their mind as architecture to its expert counterpart. One might argue that this would help to bridge the gap between popular conception of architecture represented by the first-year students and conception of architecture as distilled from the expert knowledge of the discipline. Such a position seems to be demanded a substantial convergence (of students) in the need to be more deeper understanding of architecture that have emerged from education. Such a position also seeks an answer to the question how is the nature of architecture to be brought into the scope of the first-year students more openly and how might we contribute them with having (achieving) an unbiased pre-educated state of minds where one open and curious about the discipline rather than the other way round. (or in another words, how might we orient them toward being more knowledgeable and open agents before choosing the discipline). Another conclusion might be drawn via directly targeted to the very core of the disciplinary knowledge which possesses inherent traditions distilled from both academic and occupational domains (mainly expert in character) those which also largely orchestrate identities of architecture. 
This approach, that may be catastrophic at its most extreme, mainly deals with the revisionist self-critical question of how architecture might be changed. Such a position concentrates on the findings (also on the question of "what architecture is all about.") especially on the basis of change. The nature of the issues addressed under this position may vary considerably (from conceptual towards more instrumental and technical).

It is important to stress that neither of these conclusions should be viewed as one stepped, narrow, prescriptive formula. Surely with the increase of similar studies the situation will be able to be understood clearly and handled from different perspectives, scales and frameworks. This study is aimed to be part of baseline data for carrying out future investigations, a step toward more systematic analysis of changing state of today's architectural education and a larger/global effort to map this phenomenon with its possible effects in architectural education.

\section{CONFLICT OF INTEREST}

No conflict of interest was declared by the authors.

\section{FINANCIAL DISCLOSURE}

The authors declared that this study has received no financial support.

\section{ETHICS COMMITTEE APPROVAL}

Ethics committee approval was not required for this article.

\section{LEGAL PUBLIC/PRIVATE PERMISSIONS}

In this research, the necessary permissions were obtained from the relevant participants (individuals, institutions, and organizations) during the survey and in-depth interviews.

\section{REFERENCES}

Akin, O. (2001). Variants in design cognition. In C. M. Eastman, M. McCracken \& W. Newstetter (Eds.). Design knowing and learning: Cognition in design education. Elsevier.

Akin, O., \& Akin C. (1996). Frames of Reference in Architectural Design: Analysing the Hyper Acclamation (A-h-a-!), Design Studies, 17, 341-361.

Anderson, S. (1987). The fiction of function, Assemblage, 2, 18-31.

Bartlett, F. C. (1995) Remembering: A study in experimental and social psychology. Cambridge University Press.

Baudrillard, J. (2007). Utopia deferred: Writings for Utopie (1967-1978). (trans.) Stuart Kendall. Columbia University, New York, Semiotext(e).

Boullée, E. L. (1976). Architecture, Essay on Art. In H. Rosenau (Eds.). Boullée \& Visionary architecture. New York, Harmony Books.

Cary, J. (2017). Design for good: A new era of architecture for everyone. Island Press. 
Choay, F. (2005). Utopia and the anthropological status of built space, In Exit Utopia: Architectural Provocations 1956-1976, Munich, Prestel.

Colquhoun, A. (1981). Essays in architectural criticism: Modern architecture and historicity. Cambridge, Mass., MIT Press.

Craig, D. L. (2001). Stalking Homo Faber: A Comparison of research strategies for studying design behavior. In C. M. Eastman, M. McCracken \& W. Newstetter (Eds.). Design knowing and learning: Cognition in design education, Elsevier.

Devlin, K. (1990). An examination of architectural interpretation: Architects versus non-architects. Journal of Architectural and Planning Research, 7 (3), 235-244.

DiMaggio, P. (1997). Culture and cognition. Annual Review of Sociology, 23, 263-287.

Gadamer, H. G. (1976). Philosophical hermeneutics. University of California Press.

Gombrich, E. (1969). In search of cultural history: The Philip Maurice Deneke Lecture 1967. Clarendon Press.

Harries, K. (1997). The ethical function of architecture. Cambridge, Mass. The MIT Press.

Hegel, G. W. F. (1943). Philosophy of right. Oxford University Press.

Hollein, H. (1968). Everything is Architecture. Bau, no. 1/2.

Jacob, F. (1993). The logic of life, a history of heredity. Princeton Science Library.

Jameson, F. (2012). Varieties of the utopian. In Atlas of transformation, JRP-Ringier.

Jauss, H. R. \& Benzinger, E. (1970). Literary history as a challenge to literary theory. New literary history, no. 2 (1, A Symposium on Literary History).

Johnson, E. (1988). Expertise and decision under uncertainty: Performance and process. In The nature of expertise, Hillsdale New Jersey, Lawrence Erlbaum Associates.

Kohls, C., \& Scheiter, K. (2008). The Relation between Design patterns and schema theory. In Proceedings of the $16^{\text {th }}$ Conference on Pattern Languages of Programs (PLoP). Nashville, ACM.

Krippendorff, K. (2004). Content analysis: An introduction to its methodology. Sage Publications Inc.

Lawson, B. (2004). Schemata, Gambits and Precedent: Some factors in design expertise. Design Studies, 25 (5), 443-457.

Minsky, M. L. (1997). A Framework for representing knowledge. In Mind Design II. J. Haugeland. Cambridge, Massachusetts, A Bradford Book, The MIT Press.

More, T. (1988). Utopia. Cambridge University Press.

Newell, A. (1969). Heuristic programming: Ill-structured problems, Progress in Operations Research, 3, 361-413. 
Oxman, R. (1994). Precedents in design: A computational model for the organization of precedent knowledge. Design Studies, no. 15 (2), 141-157.

Oxman, R. (2005). The Conceptual content of digital architecture: A content analysis in design. Arquitettura Revista, 1 (1).

Pevsner, N. (1957). An outline of European Architecture. Penguin.

Piaget, J. (1952). The Origins of Intelligence in Children. New York: International University Press.

Piaget, J. \& Inhelder, B. (1969). The psychology of the child. Basic Books.

Pople, H. (1982). Heuristic methods for imposing structure on IllStructured problems: The structuring of medical diagnostics, in, Artificial Intelligence in Medicine. Boulder Colorado, Westview Press.

Popper, K. (1974). The Poverty of Historicism. Routledge and Kegan Paul. Popper, K. (1945). Open Society and Its Enemies. (2nd ed.). Routledge.

Reitman, W. (1964). Heuristic Decision Procedures Open Constraints and the Structure of Ill-Defined Problems, New York, John Wiley \& Sons Inc., pp 282-315.

Rowe, C. \& Koetter, F. (1984). Collage city. Cambridge Mass., The MIT Press.

Rumelhart, D. E. (1980). Schemata: The building blocks of cognition. In Spiro R. J, Bertram C. B. and William F. B. (Eds.). Theoretical issues in reading comprehension: Perspectives from cognitive psychology, linguistics, artificial intelligence and education. Newark, International Reading Association.

Simon, H. (1973). The structure of ill-structured problems, Artificial Intelligence, 4, 181-201.

Tafuri, M. (1976). Architecture and Utopia: Design and the Capitalist Development, (trans.). Barbara Luigia Penta. Cambridge Mass., London, England, The MIT Press.

Tschumi, B. (2012). Architecture concepts: Red is not a color: Rizzoli.

Vitruvius (1914). The ten books on architecture. Harvard University Press.

Vidler, A. (2001). Diagrams of Utopia, in C. Zegher and M. Wigley (Eds.). The activist drawing: Retracing situationist architectures from Constant's New Babylon to beyond. Cambridge Mass., London, England, The MIT Press,.

Voss, J. \& Post, T. (1988). On the Solving of Ill-structured problems, in, The nature of expertise. Hillsdale New Jersey, Lawrence Erlbaum Associates.

Weber, R. P. (1990). Basic content analysis. Sage Publications, Inj.

Webster, H. (2008). Architectural education after Schön: Cracks, blurs, boundaries and beyond, Journal for Education in the Built Environment, 3 (2), 63-74.

\section{Resume}

Hakan Anay has bachelors, masters and Ph.D. degrees in architecture from the Middle East Technical University. Fields of interests are architectural design, 
design research, design criticism and theory. He is one of the editors of the Architecture Theory Library project in ESOGU with Ülkü Özten.

Ülkü Özten holds masters and Ph.D. degrees in Architecture from the Middle East Technical University. She teaches architectural theory and conducts design studio in Osmangazi University Department of Architecture. Fields of interests are architectural theory, design and epistemology. She is one of the editors of the Architecture Theory Library project in ESOGU with Hakan Anay. 